\title{
Endoscopic biliary recanalization with a needle- knife in post liver-transplant complete anastomotic stricture
}
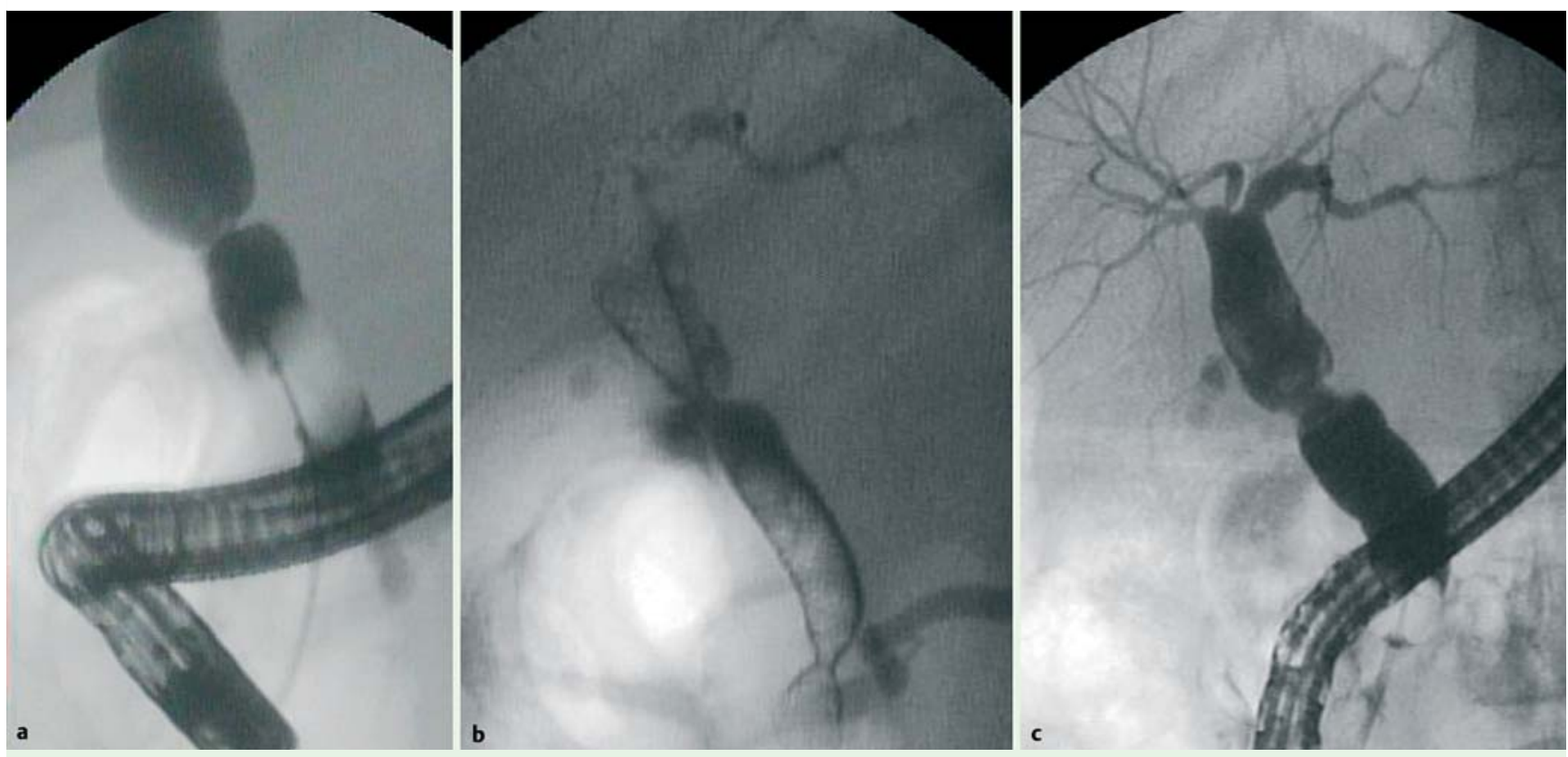

Fig. 1 Retrograde cholangiogram. a Tight biliary anastomotic stricture. b Fully covered self-expandable metallic stent (FCSEMS) placed after stricture puncture. Note two stent compressions, one proximal at the stricture site and a distal one at the ampullary level; no sphincterotomy was performed. $\mathbf{c}$ Fluoroscopic view of stricture resolution after stent removal 6 months later.

Biliary strictures are challenging situations in post liver-transplant patients, occurring in up to $15 \%$ after deceased orthotropic liver transplant (OLT) and 32\% after living donor liver transplant [1]. Endoscopic treatment is established as firstline therapy for these patients, more recently using fully covered self-expandable metallic stents (FCSEMS) [2].

A 62-year-old man, who had received an OLT 9 months earlier due to hepatitis C, presented with jaundice, elevated liver enzymes and dilated intrahepatic ducts. During endoscopic retrograde cholangiopancreatography (ERCP), after failed attempts to pass a guide wire through the stricture ( Fig. 1 a), a decision was made to puncture the stricture with a needleknife. The needle-knife was advanced through the papilla and, under fluoroscopy, the stricture was punctured by advancing the needle-knife with pure-cut current ( Video 1$)$. The guide wire was then advanced and contrast injected to

Table 1 Endoscopic biliary recanalization with a needle-knife and stenting in two post liver transplant patients.

\begin{tabular}{|lll|}
\hline & Patient $\mathbf{1}$ & Patient $\mathbf{~}$ \\
\hline Sex, age & M, 62 years & F, 66 years \\
\hline FCSEMS, mm & $10 \times 80$ & $10 \times 60$ \\
\hline $\begin{array}{l}\text { Direct bilirubin, } \mathrm{mg} / \mathrm{dL} \\
\text { (normal range } 0-1.0 \mathrm{mg} / \mathrm{dL} \text { ) }\end{array}$ & \\
$\quad$ Initial & 8.2 & 10.7 \\
$\quad$ After stent removal & 0.5 & 0.8 \\
\hline Alkaline phosphatase, U/L & & \\
(normal range $40-130 \mathrm{U} / \mathrm{L}$ ) & & 227 \\
\hline Initial & 185 & 102 \\
\hline After stent removal & 66 & \\
\hline
\end{tabular}

M, Male; F, female; FCSEMS, fully covered self-expandable metal stent.

confirm the intraductal location. The FCSEMS was placed ( Fig. 1 b). After 6 months the metal stent was removed, with stricture resolution shown by radiograph ( Fig.1c), clinical and biochemical improvement ( $\bullet$ Table $\mathbf{1})$.

A 66-year-old woman with autoimmune hepatitis, who had undergone an OLT 29 months earlier, presented with jaundice, elevated liver enzymes, and dilated intrahepatic ducts. The guide wire could not be advanced through the stricture ( Fig.2a). Needle-knife puncture of the stricture was performed, and a FCSEMS was placed ( Fig. $\mathbf{2 b}$ and Video 2 ) and then left in place for 6 months, with

\section{Video 1}

Retrograde cholangiogram demonstrating a tight biliary anastomotic stricture which was punctured by advancing the needle-knife with pure-cut current. Notice the contrast flow once the needle-knife is advanced. The guide wire is gently passed and contrast injected to confirm the intraductal location. Finally, a fully covered self-expandable metallic stent (FCSEMS) is placed. 


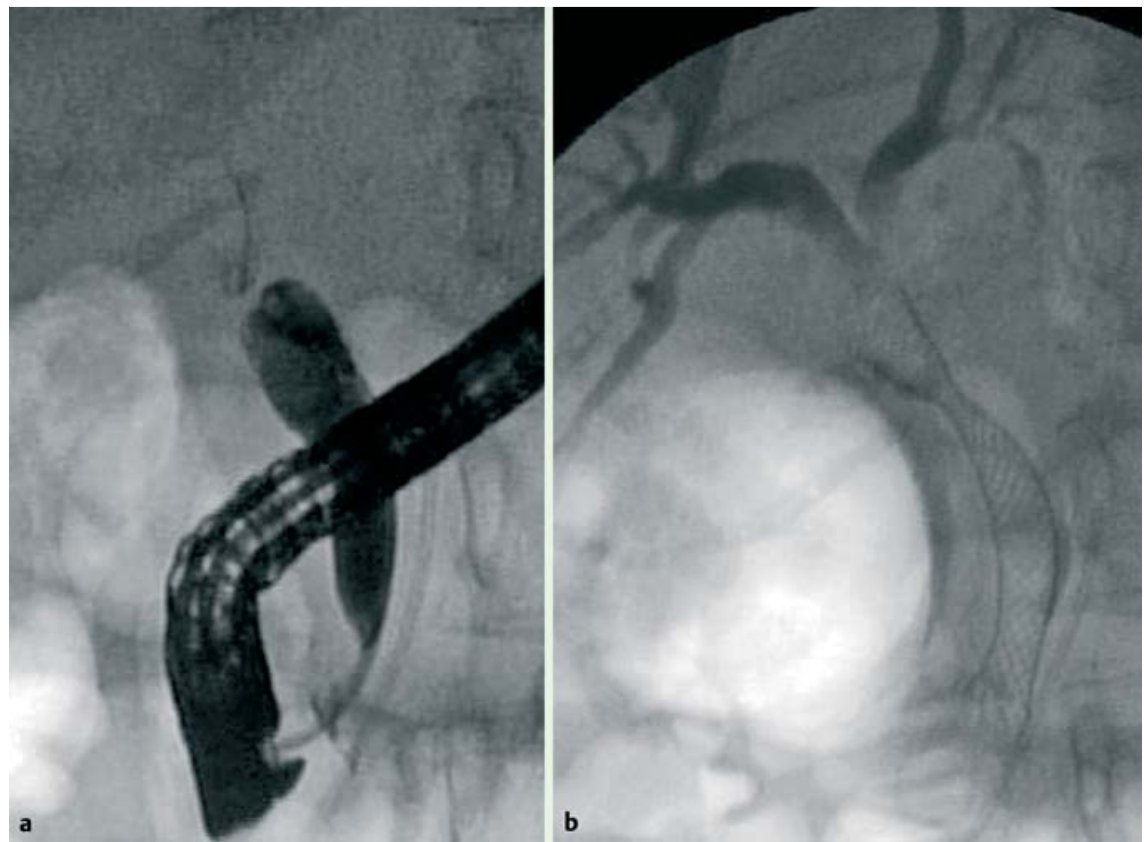

Fig.2 Endoscopic retrograde cholangiopancreatography (ERCP) showing: a tight biliary anastomotic stricture; $\mathbf{b}$ fully covered self-expandable metallic stent (FCSEMS) placed after stricture puncture. Note stent compression at the stricture site.

\section{Video 2}

Similar to the first case, a tight stricture prevented passage of the guide wire, and upstream duct access was gained through the same puncture technique using a needle-knife. Once again, notice the contrast flow while the needle-knife traverses the stricture. At the end, a fully covered self-expandable metallic stent (FCSEMS) was placed.

stricture resolution shown by radiolography ( $\bullet$ Table 1 ). No early or late complications were observed.

Biliary recanalization has been described using video cholangioscopy [3] and a specific puncture needle $[4,5]$. We describe biliary recanalization using a regu-

\section{F. P. Martins, G. A. De Paulo,} E. P. Macedo, A. P. Ferrari

Endoscopy Unit, Hospital Israelita Albert

Einstein, São Paulo, Brazil

\section{References}

1 Akamatsu N, Sugawara Y, Hashimoto D. Biliary reconstruction, its complications and management of biliary complications after adult liver transplantation: a systematic review of the incidence, risk factors and outcome. Transpl Int 2010; 24: 379-392

2 Martins FP, de Paulo GA, Contini ML et al. Partially covered SEMS versus multiple plastic stents for biliary stricture after deceased OLT. Endoscopy 2011; 43: A346

3 Itoi $T$, Ishii $K$, Tsuji $S$ et al. Diagnostic videocholangioscopy using narrow-band imaging and recanalization by rendezvous technique for difficult benign biliary stricture. Dig Endosc 2009; 21: $108-112$

4 Gupta K, Aparicio D, Freeman ML et al. Endoscopic biliary recanalization by using a needle catheter in patients with complete ligation or stricture of the bile duct: safety and feasibility of a novel technique (with videos). Gastrointest Endosc 2011; 74: $423-$ 428

5 Artifon E, Lopes T, da Silveira E et al. Endoscopic recanalization following accidental ligation of the common hepatic duct. A new technique. Rev Gastroenterol Mex 2010; 75 : $191-194$

strictures are short and therefore suitable for this technique. A limitation would be the presence of long or complex strictures. Magnetic resonance cholangiography should be performed to confirm short stricture and biliary dilatation.

Perforation and bile leakage are possible complications. We advise placing a FCSEMS to prevent leakage.

Long-term safety and outcomes are to be determined. Percutaneous or surgical procedures could be avoided.

\section{Endoscopy_UCTN_Code_TTT_1AR_2AG}

\section{Competing interests: None}

